\title{
NAS FRANJAS DO RURAL-URBANO: MENINAS ENTRE A TRADIÇÃO E A MODERNIDADE
}

\author{
Dulce C. A. Whitaker *
}

RESUMO: Este artigo gira em torno da possibilidade de reinterpretar dados de pesquisa do passado, à luz das Teorias da Complexidade, conectando-os a dados atuais para conseguir explicaçōes mais compreensivas. São tomados então alguns dados de minhas pesquisas sobre o rural-urbano, a saber: dados quantitativos do Censo de Assentamentos Rurais do Estado de São Paulo sobre as expectativas dos pais em relação à escolarização de meninos e meninas (anos 90); dados qualitativos de uma pesquisa com redaçóes escolares realizada na região de Araraquara no início dos anos 80 . Construindo-se uma ponte entre as duas situaçōes, o argumento central é o de que questão das meninas na zona rural deve ser discutida levando-se em conta a relação rural-urbano e superando-se essa dicotomia sob a ótica da história recente do país. Observase então que as transformações pelas quais passa a sociedade nacional se refeletem no campo e a conexão entre os dois momentos enfocados (anos 90 versus início dos anos 80) é reveladora de que os germens dessas mudanças já se anunciavam nas relaçôes de algumas meninas que criticavam a sobrecarga do trabalho doméstico sobre os próprios ombros, principalmente sobre os de suas mães.

Palavras-chave: Criança. Trabalho doméstico. Aspirações à escolarização. Rural-urbano. Mudança social no campo.

ON THE FRINGE OF URBAN RURALITY:

GIRLS BETWEEN TRADITION AND MODERNITY

ABSTRACT: This paper centers on the possibility of re-interpreting past research data in the light of Complexity Theories, connecting them to present data to yield more understandable explanations. From such data of my research about rural-urban environments as: quantitative data from the Census in rural settlements in the State of São Paulo as for parents' expectancies about boys and girls schooling (in the 90s);

Pesquisadora do Cnpq e da Vunesp no Programa de Pós-Graduação em Sociologia da UnesP em Araraquara. 
qualitative data of a research on school writings conducted in the region of Araraquara in the early 80s. Linking both situations, the central argument is that the issue of girls in the rural environment should be discussed taking into account the rural-urban relationship and exceeding this dichotomy under the prism of the recent History of Brazil. It is then observed that the transformations the national society has been through reflect in the countryside. Besides, the connection between the two moments in focus (90s vs early 80s) reveals that the germs of such changes can already be found in the essays of some girls who criticized the overload of housework on their shoulders and especially on their mothers' shoulders.

Key words: Girls. Housework. Aspirations to be schooled. Rural-urban environments. Social changes in the countryside.

\section{Introdução}

$\mathrm{O}$

que é ser menina? O que é ser menina em cada espaço ou camada social? Numa sociedade como a nossa, cuja formação complexa criou subculturas heterogêneas, pensar em meninas na zona rural coloca mais questôes do que as responde.

Quando se levam em conta questões teóricas já enfrentadas pelos estudiosos das relações de gênero, conclui-se com perigosa facilidade que a mulher e a menina estáo sempre excluídas dos espaços masculinos, por mais que estudos específicos demonstrem que isso nem sempre ocorre. ${ }^{1}$

Por outro lado, forçoso é reconhecer que o esforço de produzir a mulher submissa e excluída, cujo padrão ideal acaba conformando, em maior ou menor grau, a cada uma de nós, exige programação especial na infância. Tal programação configura uma verdadeira "didática da gravidez" (Whitaker, 1989) e processos dolorosos muito bem registrados por Belotti, 1983.

Ao longo da vida, meninas sofrem um processo de socialização que as prepara para a desvantagem, com menores expectativas de escolarização e profissionalização do que os meninos. No meu livro Mulher e homem: $O$ mito da desigualdade descrevo a complexidade sociológica do processo cuja base reside justamente nas ambigüidades do trabalho doméstico (Whitaker, 1989). Veremos agora que, mesmo para as condições de vida na zona rural e naquelas regiōes que chamo as franjas do rural-urbano, o trabalho doméstico é referencial importante na socialização das meninas.

Mas há que ser otimista! Escrevi recentemente um texto sobre "mulher e educação" para um livro sobre o Brasil na virada do milênio, 
no qual descrevo as conquistas femininas especialmente via educação escolarizada. Os padrões ideais do que é ser mulher (e do que é ser homem) estão sofrendo pressão dos padrões reais que emergem do mundo do trabalho e da complexidade das profissões ligadas ao avanço tecnológico. Mulheres invadiram as universidades, lideram movimentos sociais e tomam de assalto o espaço da política. Este não é o tema deste artigo, mas resolvi situá-lo porque em alguns momentos das minhas reflexões sobre as meninas estarei buscando a perspectiva otimista que pode encontrar, mesmo em populações vulneráveis, alguns germens e sintomas dessas mudanças.

É preciso evitar o mecanicismo das análises apressadas que reproduzem enfoques sem preocupação com a dialética dos processos. Para tanto, cumpre lembrar que o trabalho de mulheres e meninas não é o mais pesado no mundo rural. $\mathrm{O}$ que se passa é que a dominação que pesou sobre elas no passado implica deveres, o que diversifica suas atividades, tornando-as extremamente complexas.

Vejamos como Fussel e Fussel descreveram a situação da mulher inglesa no campo do tempo dos Tudors até a era Vitoriana.

O pai e marido era o cabeça da família, não só reconhecido como aceito. A mãe e esposa, embora ativamente envolvida em ajudar a sobrevivência da família com seus laticínios e criaçóes, seu fiar e tecer, suas conservas e destilados, aceitava sua submissão ao marido (...). Ela era a inferior, mas não a infeliz parceira na aventura matrimonial e ela não se revoltava contra sua carga. E sem dúvida ela tinha suas maneiras de impor seus desejos, embora ostensivamente sob o controle desse ser superior, o homem. (Fussel e Fussel, 1985) ${ }^{2}$

O trecho acima é ainda real para muitos grupos sociais pelos vastos brasis, e não só rurais. Mas vejamos agora, em regiōes específicas, como, por um lado, as expectativas e os padrões em relação às meninas estão em transformação para certos grupos rurais e, por outro lado, o estigma dos deveres femininos e trabalhos domésticos ${ }^{3}$ marcou, em passado recente, meninas diversas em espaços sociais determinados.

\section{I - Meninas na zona rural: espaços diferenciados}

Pensar em meninas na zona rural é pensar uma complexidade que envolve questōes teóricas fundamentais: relaçōes de gênero, diversidade cultural e de espaços sociais, classes sociais, relaçóes raciais. É preciso realmente, como aconselha Morin, uma visão poliocular para dar conta do tema (Pessis-Pasternak, 1993). Até porque não podemos mais separar 
facilmente o rural do urbano, unificados pela expansão e pelo aprofundamento das relaçôes especificamente capitalistas no campo.

Há alguns anos, escrevendo um ensaio sobre "cultura escolar e espaço social", observei, partindo de reflexôes de Walter Benjamin sobre a criança, como esse autor "destrói implacavelmente duas ficções da ideologia burguesa: a crença numa essência absoluta da infância e a crença numa essência absoluta do ser humano" (Whitaker, 1995b). "A burguesia vê sua prole enquanto herdeiros, os deserdados os vêem como ajudantes, vingadores, libertadores" (Benjamin apud Whitaker, 1995b).

Reflexão de impressionante lucidez, cai sobre o leitor como raio iluminador, que desvela a ideologia comprometida com a visão romântica da infância.

No mesmo texto, vou adiante, porém, indagando se a dicotomia entre as duas classes fundamentais pode dar conta ainda hoje de um mundo que se torna multicultural - no Terceiro Mundo, pela própria história da colonização, marcada por catástrofes sociais dilacerantes, e no centro do industrialismo mundial, pela atração que este exerce sobre os povos explorados de todo o planeta.

Assim, um caleidoscópio de infinitas miríades de espaços socioculturais é criado e re-criado pelo industrialismo, o qual avança sobre múltiplas e diferenciadas estruturas tradicionais, deixando-se ao mesmo tempo "invadir" por "subculturas exóticas", desarticulando e recriando a seu bel-prazer os novos espaços e os novos atores sociais da chamada pós-modernidade. Tal recriação articula maquiavelicamente o arcaico e o moderno, mantendo certas estruturas, no sentido de propiciar os melhores resultados para o processo de acumulação mundial.

Não cabe dissertar aqui sobre o processo de globalização, mas ele compõe hoje o pano de fundo de qualquer análise sociológica que leve em conta a totalidade. ${ }^{4}$ Importa aqui recortar dessa totalidade um aspecto da modernização do campo no Brasil, para inserir entre suas contradições a questão do processo de socialização das crianças - no caso meninas (em contraponto com os meninos), em diferentes espaços desse rural, profundamente afetado pela fusão com o urbano.

Impossível, no entanto, pensar o Brasil como um todo, nos limites de um texto. Das palafitas da Amazônia aos pampas do Sul, os espaços diversificam-se exponencialmente e este balanço sequer está completo. Há cientistas sociais que ainda raciocinam em termos de casa-grande e senzala, espaço público e privado, dois brasis, casa e rua, e nesse esquema dual dão a mulher como invisível ou prisioneira. No entanto, a nova 
história e a Sociologia, tendo colocado seu foco sobre mulheres e meninas, descobriu-as atuando exatamente nos momentos e locais nos quais sua presença fora negada. ${ }^{5}$

Para escapar às armadilhas dualistas cumpre, em primeiro lugar, reconhecer a impossibilidade de dar conta do tema "meninas na zona rural" de forma abrangente. Em seguida, devemos recortar alguns espaços sociais nos quais podemos captar meninas na sua concretude, para só então dialetizá-las, alçando vôos teóricos mais consistentes. Em suma: construir o cenário (espaços sociais considerados) e explicar os atores (meninas nesses espaços).

Ajusto então o meu foco sobre o estado de São Paulo. Pólo de atração, concentra migrantes do país todo e sua área rural é das mais complexas, já que a modernização da agricultura, articulando o arcaico ao moderno, criou aí contradiçôes ainda não de todo equacionadas.

Para ter idéia dessa complexidade, basta tomar a região agrícola mais rica do país, que compreende o centro e o nordeste do estado, na qual se encontram alguns dos mais desenvolvidos municípios brasileiros (Ribeirão Preto, por exemplo) e encontraremos nela toda heterogeneidade e todas as contradiçóes que marcam a modernização via complexo agroindustrial. Um balanço dessa complexidade pode ser extraído do meu artigo citado acima (Whitaker, 1995b).

Fazendo dele uma síntese, direi apenas que nesse cenário o complexo cafeeiro foi substituído pelo complexo agroindustrial sucroalcooleiro e/ou da laranja, sem eliminar as desigualdades, ao contrário, aprofundando-as. Até porque não modernizou as relações de trabalho. Por outro lado, resistências e permanências compõem especificidades por detrás da "mesmice" da paisagem canavieira. Processos de desruralização e desurbanização esvaziam pequenas cidades que se transformam em acampamentos de trabalhadores volantes, a eliminação da diversidade provoca conseqüências deletérias para o meio ambiente e o desaparecimento do pequeno proprietário, cuja ação era menos danosa, acentua o problema. É preciso lembrar ainda que o próprio setor, dito modernizado, carece de homogeneidade, já que diferenciadas formas de recrutar mão-de-obra se formaram como oportunismo dado por cada momento da produção.

Paradoxalmente, num campo que se quer esvaziado, multiplicamse assentamentos de reforma agrária, processo que se intensificou a partir do governo Montoro e em relação aos quais temos desenvolvido estudos especiais desde o final dos anos 80 . 
Nosso primeiro trabalho realizado, um censo de todos os assentamentos do estado, ${ }^{6}$ constitui-se num excelente termômetro para medir avanços na posição da mulher no mundo rural e que devem ser inicialmente registrados.

O censo em questão atingiu mais de três mil famílias no estado todo e seus dados expressam um universo rural com representações de populações das mais diversas regiões do país, daí a validade dos seus resultados como expressão de mentalidades em transformação. Sabemos todos que, em relação às meninas, sempre se desenvolvem menos expectativas e se alimentam aspirações mais modestas em relação à educação escolar e ao trabalho (Whitaker, 1989) - o que pode ocorrer com maior ou menor intensidade em qualquer camada ou espaço social.

Pois bem, entre os campos do questionário utilizado para realização do censo, havia um específico, dedicado à escolarização, cujos resultados foram, de certa forma, surpreendentes.

Informatizados os resultados, foi possível interpretá-los por D.I.R.A.s, ${ }^{7}$ o que permitiria levar em conta as diferenças no grau de modernização da agricultura como variável condicionadora de alguns resultados (...) no caso da educação escolar a análise revelou resultados surpreendentes. Não importava o grau de modernização da agricultura na D.I.R.A. considerada, não importava a trajetória anterior do grupo nela assentado, não importava o grau de politização da luta que levara ao assentamento, as maiores porcentagens nas respostas dadas às questōes que direta ou indiretamente medeiam aspiraçōes por escolarização apontavam sempre na direção de uma grande valorização da escola (...). As variações (entre as D.I.R.As.) nunca eram significativas e nunca apontaram para falta ou ausência no desejo de escolarização para meninos ou meninas, já que a variável sexo foi considerada numa perspectiva de gênero. (Whitaker, 1991)

Não vou sobrecarregar o texto com dados estatísticos, já que este artigo é uma tentativa de atingir o concreto de forma dialética - mais no sentido de levantar ambigüidades do que no de responder a questões ainda sequer formuladas. Importa registrar que, na perspectiva dos gêneros, todas as questões relativas à escolarização foram colocadas com alternativas para meninas e meninos. O surpreendente é que, em todas as situações consideradas, interrogados sobre a idade até a qual os pais queriam que os filhos estudassem, não houve diferença significativa entre aspirações escolares para meninos e meninas. Não houve diferença, também, em relação ao tipo de escola desejado e sobre as expectativas que alimentam com referência a estudos para filhos e filhas. ${ }^{8}$

Por trás da frieza dos dados encontram-se populações batidas por vagas de sofrimento e luta que incorporam valores democráticos, 
aconselhando prudência ao pesquisador urbano que pensa o homem rural como portador do atraso. Assim, a luta feminina e o avanço da mulher no território da escolaridade, um fenômeno histórico que faz parte da totalidade, reflete-se positivamente sobre meninas da zona rural, que vivem numa situação muito específica de ocupações e assentamentos, alterando o imaginário dos pais em relação ao futuro, o que permitirá, para muitas delas, alcançar patamares mais elevados de escolarização.

\section{II - As representações das meninas}

Mas deixemos o imaginário dos pais e passemos às próprias meninas. Marilena Chauí criticou o "discurso sobre" - discurso teórico que ignora o sujeito e se deixa contaminar pela ideologia. Aconselha que se analise o "discurso de", que permite a fala das crianças. Para conseguir fragmentos desse discurso vou em busca de redações escolares colhidas em situação experimental, com controle rigoroso da metodologia empregada, e que serviram como fonte a vários dos meus trabalhos nos anos 80 (Whitaker, 1984). Resgato nelas o discurso das meninas e, na perspectiva da visão poliocular, compreendo a necessidade "do olhar que olha o olhar que olha" (Pessis-Pasternak, 1993).

Quando analisei essas redações nos anos 80, extraí delas muitas informações importantes sobre o tema que abordava - a ideologia e o controle do trabalhador da cana. ${ }^{9}$ Extraí também muitas representações importantes sobre a cultura rural em desarticulação e a reconstrução possível. Sobre meninos e meninas, observei então:

Até nove ou dez anos, as crianças descrevem seu cotidiano sem grandes diferenças no que se refere a horários, brincadeiras e até auxílio às mães no trabalho doméstico. A partir dessa idade, o lazer dos meninos se amplia extraordinariamente: andar de bicicleta, trocar figurinhas, correr atrás do homem das figurinhas, jogar futebol, nadar na cachoeira etc. Nesses mesmos momentos, as meninas dedicamse aos trabalhos domésticos ou cuidam dos irmãos menores. (Whitaker, 1989)

Tais interpretações foram extraídas de uma quantidade enorme de outras interpretaçôes sobre a infância rural e sobre a escola. Relendo meus trabalhos de então descubro que não extraí das redações as meninas em questão, naquilo que elas tinham de mais específico como gênero construído num espaço complexo, a saber, suas próprias representações - conformidade ou resistência - diante dessa socialização diferenciada que as preparou para serem as mulheres que hoje são. 
Trata-se de tentar desvendar agora se no processo de socialização de meados dos anos 80 estavam dados os germens das transformaçôes positivas que procuro detectar neste ensaio.

Para tanto levo em conta as redaçóes das meninas entre 9 e 11 anos, momento ao qual se refere a análise acima resumida, para verificar se e como aquelas meninas sentiram aquele momento crucial de suas vidas, momento no qual os meninos começavam a adquirir os privilégios do gênero masculino, libertando-se da condição de infância que até então os aproximava do feminino, ${ }^{10}$ momento em que a menina deveria perceber (ou não) a diferença como desigualdade.

Em suma, optei agora por "garimpar" novas representações no discurso dessas meninas, para observar num momento muito especial de afastamento entre os gêneros como reagia o sexo feminino diante do diferencial que lhe estava sendo imposto.

Busco esses dados apenas nas meninas que haviam atingido a $3^{\mathrm{a}}$, $4^{a}$ ou $5^{a}$ séries do então ensino de $1^{\circ}$ grau. As de muito tenra idade ainda não haviam passado pelo processo e mesmo as de 9 anos, quando em defasagem idade/série (cursando a 2a), ainda não haviam adquirido recursos lingüísticos para expressar idéias tão complexas. Quanto às adolescentes, suas redaçōes, extremamente alegres, expressaram, neste experimento, um mundo de sociabilidade tão intensa que não sobrou espaço para lamentações sobre o trabalho dentro ou fora de casa. ${ }^{11}$

De modo geral, as meninas, consideradas para fins deste resgate histórico, tinham boa competência lingüística, com as exceçōes esperadas. Algumas cometiam erros ortográficos, mas não a maioria. $\mathrm{O}$ tema $\mathrm{da}$ reação foi para todas as séries de então: "Descreva sua casa e um dia na sua família". Quase todas as crianças de então - meninos e meninas descreveram um coditiano familiar no qual avultavam os trabalhos femininos, ${ }^{12}$ já que o pai, cortador de cana, tratorista ou motorista, desenvolvia atividades longe da casa, num espaço sistematizado pela usina, que pouco ou nada tinha a ver com o rural tradicional. É claro que analisei também redaçôes de pequenos sítios, mas estas eram minoria no conjunto e, embora revelando crianças bem mais criativas em função do espaço menos controlado e de um trabalho menos subordinado ao capital, não apresentaram especificidades na questão dos gêneros.

Vejamos então alguns resultados de nosso resgate. As meninas contavam que suas mães se levantavam às 3 ou 4 horas da madrugada para preparar o almoço e a mochila dos trabalhadores (marido, filhos e filhas solteiras). Estes se levantavam um pouco mais tarde e iam para o trabalho. 
A menina levantava-se em seguida para ajudar a mãe. O trabalho da mãe, nesta situação, consistia em garantir a reprodução da força de trabalho, manter a casa limpa conforme exigências (nas casas cedidas pela usina), lavar e passar roupas para todos os moradores da casa. A menina participava de toda essa trabalheira, ao passo que seus irmãos meninos iam escapando para o mundo aventuroso do exterior, o que se expressava tanto em suas redaçóes como nas deles. No entanto, as meninas não percebiam qualquer injustiça nessa situação, o que parece indicar um processo de socialização bastante eficiente.

As mães cuidavam de criações e de hortas - estas, no caso das moradias da usina, manipuladas pelo assistencialismo, para garantir alimentação mais barata. Havia ainda pequenos jardins a serem cuidados. As meninas participavam de tudo e ainda cuidavam de irmãos menores, sem reclamar. Enquanto isso, as redaçóes dos meninos revelam um mundo de pescaria, cachoeiras, caça a passarinhos, passeios de bicicleta. Cumpre registrar que meninas de pequenos sítios tangenciavam mais facilmente algumas dessas aventuras, como nadar em rios e cachoeiras. Quanto às filhas dos trabalhadores das usinas, o controle era bem mais intenso.

Mas será que as meninas não percebiam mesmo a desigualdade do processo? Afinal, elas também iam cortar cana quando necessário e teriam que trabalhar, no futuro, fora dos "muros" protetores do lar.

Processos humanos são ambíguos e podem se constituir em nuanças contraditórias. Algumas representações resgatadas nessas redações ajudam a compreender melhor o momento de cada menina.

Marisa, 11 anos, pai tratorista, contou-nos que a mãe "levanta bem cedo para fazer o almoço" ao passo que o pai "levanta sete horas e vai tomar café" (grifos meus). Aprofundando a análise, numa outra leitura, esta frase, nos seus grifos, parece indicar uma comparação um tanto inquieta. Com efeito, continuando seu discurso, a menina informava: "Eu levanto cedo para ajudar minha mãe e ela limpa a casa e lava a roupa e também passa roupa”. E concluía após muitas descrições sobre tanto trabalho: "Meu pai está de férias, mas não para ele ajudá limpar casa". ${ }^{13}$

A frase é ambígua. A menina não assumiu a crítica com toda clareza, mas o modo como se expressou indica que o fato de o pai, em férias, não ajudar não lhe parecia assim tão natural. Caso contrário, por que registrá-lo?

Assim, na perspectiva de uma ciência nova, mais preocupada com a ocorrência simultânea de fenômenos contrários, surge a possibilidade de uma nova interpretação. $\mathrm{O}$ fenômeno mais evidente, em todas as redações, é a ausência de queixa aberta contra o espaço confinado e 
o peso dos trabalhos domésticos, ao qual estavam todas submetidas dentro da casa ou à sua volta. Mas do contraponto entre os horários da mãe e do pai e da afirmação sobre as suas férias emerge exatamente o contrário do que estava dado como padrão. A menina não se lamentava, mas percebia, sim, e denunciava, de forma sutil, a injustiça da situação.

Mas controlemos o otimismo. Há redações nas quais, por mais que tenha garimpado, nenhuma frase pude encontrar reveladora de contradiçóes ou ambigüidades. Assim era Juvelina, mesma idade e situação escolar de Marisa: "Eu limpo o fundo e a frente da casa (...). Eu lavo calsada todos os dias, cuido das flores, gosto muito das criaçôes". (Grifos meus).

O verbo gostar foi a constante desta redação, indicando acomodação perfeita de qualquer conflito. E não só neste caso. Garimpei na redação de Nazilda (11 anos) uma reiteração muito interessante do verbo gostar: "Minha mãe lava roupa e faz comida. Ela gosta de costurar. Meu pai gosta de assistir jogo".

O uso do verbo 'gostar', no caso acima, parece indicar lazer, já que assistir a jogo era o lazer desse pai. Assim, "costurar" (atividade diferenciada) talvez fosse, no imaginário da menina, uma forma de lazer. Ela escreveu ainda: "Minha mãe gosta de fazer bolos". Assim, enquanto o pai vai trabalhar, vai fazer pagamentos, vai construir, a mãe gosta daquilo que faz.

Ensaiemos duas interpretações, para sermos coerentes com a nova ciência. Ou simplesmente, sejamos dialéticos! Numa primeira abordagem, ao imaginário da menina, a pobre mulher esmagada pelo peso de trabalho da casa, da horta, das criações, ainda tem que gostar da situação, para ser, como queriam os Fussel, a "parceira inferior porém feliz" da relação matrimonial. Buscando o fenômeno contrário, porém, podemos inferir que certas atividades femininas artesanais, como fazer bolos e costurar, são realmente prazerosas.

Contudo, nosso otimismo desaba novamente diante da redação de Flávia Regina, 10 anos: "Meu irmão vai pescar"; e logo adiante: "Eu gosto de limpar a casa”.

Esta redação não ofereceu ambigüidades: nela a socialização diferenciada emergiu com toda nitidez. A menina não disse "Eu tenho" que limpar. Pelo contrário, ela assimilou o fato como de natureza e "gosta" daquilo que é obrigada a fazer.

Mas as redações das meninas tinham ainda outras características, algumas que são, ainda hoje, consideradas muito "femininas". Elas eram, 
às vezes, poéticas, mostrando que a rusticidade da vida e as imposições da usina não impediam a expressão lírica: "Minha casa é bonita ela tem um sercadinho de flores".

As meninas faziam ainda um inventário minucioso dos objetos de uso doméstico, mas suas colocações envolviam também um certo carinho comovente pela professora e pelos colegas. Dirão alguns que tais expressões são características da socialização diferenciada que impõe comportamento suave e terno ao caráter feminino. Também já denunciei o fenômeno (Whitaker, 1989), mas resolvi, nesse momento, observar seu lado positivo, ou seja, o seu contrário. Afinal, as mulheres acabam se beneficiando dessa maior liberdade de expressão emocional, negada aos meninos, o que também já enfatizei (Whitaker, 1989).

Assim, nesta situação específica, na qual pairava sobre crianças de ambos os sexos a ameaça do trabalho precoce, a situação dos meninos era mais vulnerável. Eles eram recrutados mais facilmente para o trabalho. Talvez por isso as meninas tenham apresentado um discurso "mais feliz". O raciocínio dialético força-me a constatar tais contradições, ainda que seja apenas para levantar problemas. E a própria situação de ambigüidade, nestas franjas do rural-urbano, parece ter provocado visóes dialéticas em algumas crianças.

Rosa Angélica, 9 anos, $4^{a}$ série, já tinha competência lingüística para expressar tais visóes, ou melhor, representações. Seu pai era fiscal no corte da cana (trabalho rural), porém a mãe era funcionária da prefeitura na cidade-dormitório em questão. A menina descreveu então um padrão mesclado de rural-urbano: a mãe, levantando-se às 4 horas da madrugada para fazer o almoço do pai, deitava-se novamente, para levantar-se às 7 horas, chamar as crianças para a escola e ir trabalhar.

Será por simples coincidência que sua redação tenha apresentado representações dialéticas sobre aspectos relacionados ao caráter dos membros da família? Observem: "Meu pai é bom e mal. Mas quando ele está nervoso: Ele não gosta que enche. Minha irmã do meio é boa e nervosa e chorona. Eu sou uma menina nervosa e boa para quem é boa para mim".

Salete, 11 anos, também mesclou padrões rurais e urbanos, e com certa expressão poética: "Minha mãe e minha irmã fica sentada debaixo do pé de jabuticabeira e eu fico brincando de casinha".

Contudo, há sempre trabalhos domésticos atravessando os momentos idílicos do discurso. Após o banho, a menina arrumava a cozinha, antes de dormir, sem qualquer reclamação. 
Encontramos ainda a situação de meninas que se preocupavam com o excesso de trabalho do pai. Rosângela, 10 anos, pai retireiro, trabalhando também numa olaria: "Nós levantemos 7 horas, tomamos café e limpamos a casa, fora meu pai" (grifos meus).

Aqui a menina procurou salvaguardar a figura do pai, cujas atividades eram pesadas, o que me pareceu justíssimo. E usou sempre o pronome 'nós', expressando o padrão de motivação intensa para ajudar a mãe, que caracteriza a maior parte das redações. Em certo momento afirma deliciosamente: "E já comemos, já lavemos a louça".

Mas há casos de pais e mães que saem juntos para o corte da cana. Aparecida de Fátima, 10 anos, conta que a mãe levantava às 5 horas, chamava o pai e ambos saíam para o trabalho. Às 5 da tarde, todos em casa novamente. Após o banho, os irmãos iam estudar, a mãe fazer o jantar e o pai (pasmem!) assistia à novela das 7. A menina, obviamente, ajudava a mãe a fazer o jantar ao passo que os meninos faziam suas lições.

Esta redação impressiona pela descrição de todas as tarefas que a menina e a mãe faziam aos domingos arrumando casa, limpando quintal, fogão, geladeira! A menina descreveu, ainda, com muita alegria, um domingo em que a casa se encheu de parentes. Feliz por brincar com os primos, ela não reclama, ao contar como o pai ordena que pegue o guaraná que estava na geladeira: "Vai logo, menina, não demora". E a casa cheia de meninos! Na hora de arrumar a "bagunça", as meninas são recrutadas. A menina descreveu a cena com muita graça: "Meus primos e meus irmãos falaram - vem logo 'hein' para nós acabarmos de brincar. Minha mãe e minha tia falaram Vocês vão limpar a cozinha”. (Grifos meus).

"Vocês" significava ela e a prima. Os meninos continuavam brincando. Mas aqui a menina resistiu, que ninguém é de ferro: "Ah! não mãe, eu falei. Minha prima falou tia eu ajudo ela”.

A prima é mais conformada: seria mais velha? A menina contou ainda como a prima se dispõe a fazer "Ki-Suco" e recordou novamente a insistência dos meninos para brincar com elas. "Vamos Aparecida, diz meu primo, vamos brincar. Não! eu vou limpar a cozinha. Eu fui e nós acabamos de limpar a cozinha".

Pois é! Depois de tudo, a tia ainda fez a menina ir pegar a mamadeira do bebê. Há que registrar, sempre, no entanto, a visão poética do imaginário feminino. Aparecida terminou sua redação contando: "Minha mãe desligou a televisão e nós fomos lá fora olhar as estrelas". 
Para esta menina, o domingo foi "delicioso". Foi o que afirmou, logo depois de registrar essa atitude tão característica do rural que consiste em contemplar o firmamento à noite, para observar estrelas.

A marca mais evidente das redações nesse momento pesquisado era, portanto, uma conformidade que não se expressava totalmente sem resistência. A leve crítica que sinalizava essa resistência se expressava, no entanto, paradoxalmente contra o pai e não contra os privilégios do irmão. É como se a menina, com mais pena da mãe do que de si própria, enxergasse a injustiça na relação marido e mulher e não nos privilégios do irmão. Uma hipótese plausível é a de que a menina tenha interiorizado as queixas da mãe contra o marido. E como as mães são sempre condescendentes em relação ao filho homem (Whitaker, 1989), o próprio discurso da mãe levava a menina a ignorar os privilégios masculinos na infância.

Silvia Helena, 10 anos, $5^{\mathrm{a}}$ série, fez uma redação que ilustra bem o padrão. É uma família de pequenos sitiantes resistindo contra o avanço da plantation de cana.

Minha mãe e meu pai acordam muito cedo, não é nem 6 horas e eles já estão de pé. A minha mãe não tem hora para dormir, pois a minha irmãzinha já não deixa ela dormir muito bem e também não tem mais hora p'rá nada. $O$ meu pai já é diferente ele começa a trabalhar às 6 horas da manhã e acaba no máximo às 6 horas da tarde e depois toma um banho muito gostoso e vai para a cama. (Grifos meus)

As meninas estavam em geral muito conscientes da necessidade que as mães têm de descansar. Era um padrão recorrente no conjunto das redações das meninas. Mas nunca propunham que os meninos ajudassem. Mostravam-se então ansiosas por aliviar a carga da mãe sem lamentarem a própria carga decorrente.

A riqueza dos dados recuperados nessa minha volta a um passado recente de pesquisa não caberia neste artigo. São nuanças e ambigüidades que não se podem quantificar. Mas elas se revelam ao pesquisador atual porque, em diferentes momentos, algumas meninas tiveram competência lingüística para expressá-las. Elas estão registradas.

Encerrarei este texto com algumas representações de Roberta, 11 anos, sobre o cotidiano de uma família muito próxima do rural. Embora morando em Santa Lúcia, essa cidade já era, à época, um enclave no meio dos canaviais e seu espaço urbano guardava, poeticamente, os resquícios do rural tradicional que o complexo agroindustrial da cana estava destruindo nas fazendas do seu entorno. Observem o discurso esclarecedor: 
Aí meu irmão levanta, toma café, troca a água dos passarinhos, se troca e vai jogar bola. Aí, Eu acordo e tomo o meu café, ligo a televisão, acordo minha irmã, abro a casa, limpo a sala, arrumo os quartos, tiro a mesa do café, minha irmã varre a casa, lava a louça, tira o pó, passa pano no chão e varre o quintal.

Ufa! Pobres meninas confinadas no espaço doméstico entre a TV e os panos de chão!

\section{Considerações finais}

O tema não oferece "conclusões". Há processos históricos em andamento. Vimos como uma categoria sociológica nova - o assentado pela reforma agrária -, cuja luta tem efeitos pedagógicos expressivos, manifesta opiniōes que sinalizam mudanças cruciais. Não por acaso, lideranças femininas despontam no movimento de luta pela terra. Mas captamos, também, meninas que hoje são mulheres, passando por um processo de socialização extremamente limitador.

Procurei nesse processo encontrar nelas os sintomas da crítica e da resistência. E eles estavam lá! Faço votos para que aquelas meninas, que hoje são mulheres, tenham conseguido superar os limites dados pela socialização via trabalhos e deveres domésticos, para alcançar uma profissionalização que lhes confira autonomia e dignidade. Afinal, isso foi possível para muitas de nós e em todas as classes sociais. Não por acaso, o país está mudando no que se refere às relações entre os sexos.

\section{Notas}

1. Maestrinas musicais e marinheiras na Veneza dos séculos XVII e XVIII, aviadoras soviéticas na Segunda Guerra Mundial, guerrilheiras, quituteiras, vendeiras, compositoras emergem por toda a história do Brasil e do mundo e são alguns exemplos contradizendo as teorias.

2. Tradução desta autora.

3. Cumpre lembrar que o trabalho doméstico não é um mal em si. Ele tem o estigma do feminino, que já se encontrava entre os gregos do período clássico. Ver, por exemplo, Pissa, 1993. Quando the retiramos o estigma, ele pode ser dividido, com prazer, entre todos os membros da família.

4. Por exemplo, crianças barbaramente exploradas na extração de cassiterita, com a qual se produz estanho, estão inseridas na cadeia produtiva mundial daquilo que se considera o ícone da modernidade - o computador, com os milagres da informática (Whitaker, 1998).

5. Ver, por exemplo, Marins, s/d.; David, 1999; Whitaker e Antunes, 1999.

6. Análise e Avaliação dos Projetos de Reforma Agrária e Assentamentos no Estado de São Paulo, CNPq/Finep/Mirad/Fundunesp; coordenação: S.M.P. Bergamasco e V.L. Botta Ferrante. 
7. D.I.R.A. $=$ Divisão Regional Agrícola no estado de São Paulo.

8. A análise trabalhou com as esperanças subjetivas (o desejo), indagando até que idade gostariam que os filhos e as filhas estudassem. E numa estratégia inspirada em Bourdieu e Passeron, captou ainda as esperanças objetivas, isto é, até que idade acreditavam que as crianças estudariam (o real). Mesmo nessa contraposição, o imaginário dos pais não faz diferenças em relação ao futuro das meninas (Censo dos Assentamentos do Estado de São Paulo).

9. Foram as crianças que me forneceram, naquele momento, a chave para desvelar a manipulação, na Ideologia, da família trabalhadora numa situação bastante específica (Whitaker, 1984).

10. Cumpre lembrar aqui que a palavra 'criança' em nossa língua é do gênero feminino, o que tem implicações sociolingüísticas a serem consideradas.

11. Até porque, se permaneciam na escola após a $5^{\text {a }}$ série, é pelo fato de que escaparam ao destino do corte da cana que afastou muitos dos seus amigos do espaço escolar. Eram diferenciadas, portanto.

12. O experimento colheu redações em três diferentes situações socioespaciais: pequenos sítios, moradias da usina de álcool e a pequena cidade que abrigava as fazendas da usina, num bairro no qual moravam os trabalhadores volantes do corte da cana. A cada situação socioespacial correspondeu um modelo de redação, mas para os alvos destas reflexōes não houve diferença na maneira como esta questão dos gêneros na infância atravessou todos os três modelos (Whitaker, 1984).

13. Respeitei a ortografia das crianças e me recuso a usar a expressão "sic", que sobrecarrega o texto e já adquiriu conotaçóes negativas. A reprodução de como as crianças escrevem, além de implicar respeito, tem aqui a vantagem de mostrar que os erros ortográficos não são tão freqüentes.

\section{Referências bibliográficas}

BELOTTI, E.G. Educar para a submissão. Petrópolis: Vozes. 1983.

FUSSEL, G.E.; FUSSEL, K.R. The English Countrywoman: Her life in farmhouse and field from Tudor times to the Victorian age. London: Bloomsbury Books, 1985.

DAVID, E. Solidariedade e sociabilidade: Mulher, cotidiano e política na periferia de Araraquara. Tese de doutorado em Sociologia, Universidade Estadual Paulista. Araraquara, 1999.

MARINS, P.C.G. Através da rótula: Sobre mediaçōes entre casas e ruas. Trabalho apresentado no $23^{\circ}$ Encontro Nacional de Estudos Rurais e Urbanos - Ceru, s/d. (mimeo).

PESSIS-PASTERNAK, G. Do caos à inteligência artificial. São Paulo: Editora da UNESP, 1993.

SISSA, G. "Filosofias do gênero: Platão, Aristóteles e a diferença dos sexos". In: Pantel, P.S. (org.), História das mulheres: A Antiguidade, Porto/São Paulo: Afrontamento, 1993. 
WHITAKER, D.C.A. Ideologia e Cultura Rural: O controle ideológico do trabalhador da cana. Tese de doutorado, Universidade de São Paulo. São Paulo, 1984 (mimeo).

. Trabalho Infantil e Industrialismo: Os paradoxos da modernidade. Trabalho apresentado no Simpósio "Televisão, Criança e Imaginário", 1998 (no prelo).

. "Menino X menina: Sexo ou gênero? Alguns aspectos cruciais". In: Serbino, R.V.; Lima Grande, M.A.R., A Escola e seus alunos: Estudos sobre diversidade cultural, São Paulo: Editora da UnEsP, 1995a.

. "Cultura escolar e espaço social”. In: Serbino, R.V.; Lima GranDE, M.A.R., A Escola e seus alunos: Estudos sobre diversidade cultural. São Paulo: Editora da Unesp, 1995b.

. Mulher - Homem: O mito da desigualdade. São Paulo: Moderna, 1989.

. Ruralidade e aspirações por educação escolar. Colloquium Revista Científica da Unoeste, Presidente Prudente, jun. 1997, vol. $1, \mathrm{n}^{\circ} 1$.

WHITAKER, D.C.A.; ANTUNES, R.A. "Mulher e o espaço político formal: O caso do Legislativo”. In: D'InCAO, M.A., Sociabilidade: Espaço e sociedade, São Paulo: Grupo Editores, 1999. 